\title{
"El legado de Julieta Kirkwood en la sociología y en el feminismo chileno"
}

Reseña bibliográfica de Julieta Kirkwood, Ser política en Chile. Las feministas y los partidos, Santiago de Chile, LOM Ediciones y Facultad de Ciencias Sociales, Universidad de Chile, 2010.

\section{Javiera Osses ${ }^{1}$ y Daniela Valencia ${ }^{2}$}

La historia del feminismo en Chile y su particular relación con la sociología data de muchos años, y de una infinidad de autoras e investigadoras que han dedicado su vida a estudiar y difundir la realidad de la mujer chilena. Una de la investigadores con mayor trascendencia y a quien están dedicadas las siguientes páginas es Julieta Kirkwood (Santiago de Chile, 1937-1985).

Socióloga y cientista política, precursora de los estudios de género en la década de los 80 en Chile, Kirkwood fue parte de una de las primeras generaciones de mujeres en recibir educación secundaria, ingresando posteriormente a la Universidad de Chile, momento que coincide con el surgimiento de movimientos estudiantiles y sociales impulsados por la revolución de mayo de 1968 en Francia. Al terminar sus estudios, en 1972, se incorpora a la Facultad Latinoamericana de Ciencias Sociales (FLACSO).

Julieta Kirkwood fue miembro del Círculo de Estudio de la Mujer, parte de la actual Universidad Academia de Humanismo Cristiano. Este Círculo estaba integrado por varias académicas e investigadoras relevantes de la época, que utilizaban este espacio para estudiar, analizar y debatir sobre la identidad femenina, los roles de género y la realidad de la mujer chilena. Con el golpe de Estado de 1973 y posterior régimen autoritario, este Círculo fue

Licenciada en Sociología, Universidad Católica Silva Henríquez, Santiago, Chile. Contacto: javi.osses.m@gmail.com

2 Licenciada en Sociología, Universidad Católica Silva Henríquez, Santiago, Chile. Contacto: valenciarojasdaniela@gmail.com 
expulsado de la Academia de Humanismo Cristiano, en 1983, dividiéndose en dos centros académicos independientes: Centro de Estudio de la Mujer y La Morada.

Cabe destacar que Kirkwood fue una participante activa de la directiva del Círculo, siendo la encargada de idear e implementar un programa para docentes con orientación feminista.

Ahora bien, en el contexto de dictadura y la profunda represión surgen movimientos sociales en oposición al régimen, entre los cuales tuvo gran relevancia el movimiento feminista en el que Kirkwood tuvo activa participación e influencia. Es importante señalar que su pensamiento crítico y su anhelo revolucionario fueron inspirados en su etapa universitaria por los movimientos sociales de 1968, pero no fue sino hasta el régimen autoritario cuando sus propuestas teóricas sobre la condición de la mujer chilena se concretaron. Este movimiento es denominado "La segunda ola feminista en Chile" y tuvo como eje principal la investigación centrada en la mujer chilena, en la que tanto el Centro de Estudio de la Mujer como La Morada fueron relevantes.

Durante los años del régimen dictatorial Julieta Kirkwood escribió grandes libros acerca de la problemática de la mujer chilena y el feminismo, entre los que podemos destacar: Tejiendo rebeldía (1987), Feminarios (1987) y Ser politica en Chile. Las feministas y los partidos (1982). Justamente es este último escrito el que profundizaremos en esta reseña bibliográfica, dado que permitió integrar la problemática de género en la sociología chilena con una mirada política y permitió comprender el movimiento feminista.

A modo introductorio podemos mencionar que Ser política en Chile. Las feministas y los partidos fue publicado por FLACSO en 1982 y reeditado en 1986 y 2010, y que es en sí un libro recopilador de la mayoría de los escritos de Kirkwood. En general los temas expuestos por la autora en este texto se relacionan con sus investigaciones políticas y sociológicas, que van des- 
de la participación de la mujer en la política, los problemas de identidad y género según los diversos sectores sociales hasta, por último, la historia del feminismo en nuestro país. Por otro lado, es importante destacar que Kirkwood trata algo bastante particular en su obra, puesto que sus trabajos feministas son considerados como "investigación-acción", lo que tiene como objetivo apuntar a lo mediato de los movimientos sociales, pero también a lo inmediato de la construcción de teoría, discusión académica, etc.

En este libro Kirkwood realiza un relato histórico sobre las mujeres en Chile, principalmente sobre su organización y sus conformaciones en relación con la política, con el objetivo de demostrar que este fenómeno no era algo novedoso en el país y que se encontraba oculto en la historia chilena. La primera ola feminista surge en la década de 1940, para exigir el sufragio femenino, y se prolonga hasta 1952, porque al lograr su objetivo estas agrupaciones y organizaciones de mujeres pierden su fuerza.

Kirkwood (1990) menciona que una de las características más destacables de las agrupaciones femeninas es que pueden perseguir diversos objetivos, formas de acción o propósitos, pero tienen como eje principal ser constituidas por mujeres y para mujeres. Además de generar una nueva forma de organización civil en Chile, se estructuran y actúan de una peculiar manera: primero, no se distinguen jerarquías, produciéndose una participación activa de cada miembro; segundo, la problemática central es la mujer y su rol en Chile; por último, la gran parte de sus participantes se autoproclama e identifica "feminista".

Aunque Kirkwood recalca la cohesión y el trabajo en conjunto que se logra en estas diversas agrupaciones de mujeres, también afirma que, dentro del movimiento feminista de la época de los ' 80 , se produce un choque de pensamientos, distinguiéndose dos grupos: políticas y feministas.

Las políticas, al plantear las problemáticas de la mujer, tomaban en consideración solo su rol de cuidadora y madre, centrán- 
dose principalmente en la familia, revirtiendo el análisis feminista y no originando una real incorporación de la mujer en el ámbito público, limitándola solo al privado. Por otro lado, las feministas planteaban estas problemáticas teniendo en consideración el cotidiano de la mujer en el que son reprimidas en varios aspectos, en especial en su núcleo familiar.

Pero políticas y feministas tenían en común buscar el reconocimiento de la emancipación de la mujer, tomando en consideración su recorrido histórico; no obstante, no hubo un acuerdo sobre la manera en que se debería llegar a esta emancipación y liberación de la mujer.

En base a esto, Kirkwood plantea dos teorías de cómo llegar a la emancipación de la mujer en la época, y es una visión que se lograr vislumbrar de la gran variedad de agrupaciones de mujeres que se formaron en este contexto. La primera es que "no hay feminismo sin democracia" (Kirkwood, 1990, p. 222); para esto, era necesario articular una lucha opositora contra el régimen autoritario, pero el problema es que solo se priorizó la problemática de la mujer en general, dejando de lado la variedad de discriminaciones que ésta vive día a día. Esta teoría es apoyada por las politicas.

La segunda es que "no hay democracia sin feminismo" (Kirkwood, 1990, p. 222), porque, con la existencia de cualquier tipo de opresión, discriminación, dominación y subordinación de las mujeres en ambas esferas, privada y pública, no existe una verdadera democracia.

Otra observación de Kirkwood es que la mujer, en su familia, se encuentra sumida en una cotidianidad dominada por el autoritarismo, sin importar el rol que cumpla (hija o madre), teniendo la autoridad y poder absoluto el hombre, denominado "jefe de familia". Este orden es considerado algo natural, generando dos ámbitos de acción en relación a lo político, uno privado y el otro público. Pero es importante destacar que esta división no nace con el régimen autoritario sino que es anterior a éste. 
El ámbito privado es vinculado a lo femenino, que engloba a lo doméstico; en cambio el público se asocia con lo masculino, que tiene acceso a lo político y a la libertad de acción. Con base en esto a la mujer se le margina de lo político (Kirkwood, 1985).

Por esta marginación, Kirkwood logra vislumbrar dos "nudos feministas" (Kirkwood, 1985, p. 68), en otras palabras, problemas que han sido difíciles de abordar para el feminismo. Estos son el nudo del saber y el nudo del poder.

El nudo del saber dimensiona la limitación que la mujer tiene sobre el saber, en el que se da por sentado cosas, valores o saberes que la limitan en su actuar, como muy bien lo ejemplifica Kirkwood, basándose en la teoría de querer-poder de Foucault: "para las mujeres, como decíamos, los valores de igualdad, fraternidad, democracia, son 'vistos' como 'desigualdad', 'opresión' y 'discriminación'. El querer saber se parece a la rebeldía” (Kirkwood, 1985, p. 69).

El nudo del poder es una consecuencia del nudo del saber, debido a que las mujeres aceptan que no tienen acceso al poder a causa de la cultura patriarcal en la que han vivido y crecido, aprobando que no luchen ni se organicen por él. El poder solo pertenece al ámbito público, pero en cambio cuando el poder es asociado a una mujer se atribuye a la casa. Para cambiar esto es importante comprender que el poder se ejerce en la acción y no se da por sí solo; para lograrlo es necesario deslegitimar el patriarcalismo y liberar al sujeto a través de un cambio cultural.

Finalmente, Kirkwood menciona que las diversas organizaciones o agrupaciones femeninas que han surgido se han transformado en espacios políticos para mujeres, aunque sus miembros no lo consideren así.

El texto de Kirkwood es de gran consistencia teórica en cuanto a temáticas de género $y$, entendiendo el contexto en que es desarrollado, se hace indispensable leerlo. Kirkwood, a través de sus páginas, permite examinar lo público y privado como ámbi- 
tos en los que se desenvuelve la mujer, además de las divisiones de género existentes en aquellos años, que explican también las divisiones de hoy.

Es también revelador, si queremos conocer y entender las diversas dificultades que han tenido, a lo largo de la historia en Chile, los diversos grupos organizados de mujeres para mantener y perpetuar su acción política, particularmente en la palestra pública. Respecto de ello, la autora analiza la obligatoriedad experimentada por las mujeres, en cuanto a la realización de los quehaceres de la casa o tareas domésticas, casi como si fuera una cuestión inerte a la mujer y que supone el desarrollo de su vida social y física.

Por último, la invitación a sumergirse en la obra de Kirkwood se justifica, porque permite reflexionar de manera útil acerca de los diversos actos y pasos que construirán una nueva historia. Estamos pues ante un momento importante en temas de igualdad de género; por lo mismo, leer a Julieta Kirkwood es una llamada a desprendernos de las limitaciones que hemos ido adquiriendo a través de nuestra construcción social y que solo coartan la construcción de una sociedad democrática para todas y todos.

\section{Referencias}

Garrido, L. A. (2011). Julieta Kirkwood, Ser política en Chile. Las feministas y los partidos. Revista Punto Género, (1), 291-294.

Kirkwood, J. (1985). Feministas y políticas. Nueva Sociedad, (78), 62-70.

Kirkwood, J. (1990). Ser política en Chile. Los nudos de la sabiduría feminista. Santiago de Chile: Cuarto propio. 